\title{
ОСОБЕННОСТИ ИСПОЛЬЗОВАНИЯ МЕТАЯЗЫКОВЫХ СРЕДСТВ В СОВРЕМЕННЫХ АНГЛИЙСКИХ ГАЗЕТАХ
}

Статья посвящена рассмотрению социолингвистических особенностей британской прессы, коррелирующих с их информационно-содержательным и воздействующим потенциалом на читателя посредством различных метаязыковых средств. Анализ газетного дискурса и определение в нем метаязыка посредством метаязыковых операторов свидетельствует о возможности уточнения, во-первых, пексики с точки зрения происхождения, во-вторых, набора субъязыков современного говорящего и, в-третьих, динамических процессов в лексике

Газетный дискурс как процесс речевой коммуникации в печатных СМИ проявляется динамическим когнитивно-коммуникативным явлением. Текст газеты характеризуются тем, что в нем быстрее находят отражение и фиксируются многочисленные изменения языковой действительности. Сочетающаяся в таком тексте информационно-содержательная функция с функцией убеждения выражается различными метаязыковыми средствами.

Метаязык газеты «строится) посредством метаопе раторов, которые могут указывать на, во-первых, набор субъязыков современного говорящего, во-вторых, пексику с точки зрения происхождения и, в-третьих, динамические процессы в пексике.

Так, в работе представлены результаты анализа метаязыковых средств в современных английских газетах, выявлены различные языковые приемы как одна из главных причин интенсификации языковой рефлексии современной публицистики.

Носитель языка часто комментирует слова с точки зрения их происхождения. Социально-экономические и культурные связи между языковыми коллективам, а также развитие этнических контактов способствуют процессу заимствования иноязычной лексики. Свою речь говорящий часто обогащает иноязычными словами, которые маркирует метаоператорами. Указывая на заимствования, говорящий также выражает через метаоператоры оценочное отношение к иностранному слову. Метаоператоры, указывающие на динамические процессы в лексике, показывают, что словарный состав языка развивается согласно происходящим в нем процессам: постоянное пополнение новыми словами и исчезновение устаревших слов.

В связи с тем, что социолингвистические особенности современной прессы, в целом, и английской, в частности, взаимообусловлены с динамикой метаязыковых средств, в работе также дана классификация метаязыковых средств газетного языка по графико-орфографическим признакам - по знакам препинания и по шрифту.

Ключевые слова: метаязык, метаязыковые средства, метаоператоры, газетный дискурс, английские газеты.

\section{J. Pirverdieva}

\section{FEATURES OF USE OF METALANGUAGE MEANS IN MODERN ENGLISH NEWSPAPERS}

The article is devoted to the sociolinguistic features of the British press, correlating with their information-content and impact potential on the reader through various metalanguage means. The study of newspaper discourse and the revealing of metalanguage in it by means of metalanguage operators testify to the ability to determine, firstly, lexis from the point of view of origin, secondly, the set of sublanguages of the modern speaker and, thirdly, dynamic processes in lexis.

Newspaper discourse as a process of verbal communication in print media is manifested by a dynamic cognitive-communicative phenomenon. The text of the newspaper is characterized by the fact that it quickly reflects and fixes numerous changes in linguistic reality. The informational content function with the persuasion function combined in such a text is expressed by various metalinguistic means.

The metalanguage of the newspaper is "built" by means of meta-operators, which may indicate, firstly, a set of sublanguages of the modern speaker, secondly, vocabulary from the point of view of origin and, thirdly, dynamic processes in vocabulary.
Thus, the paper presents the results of the analysis of metalinguistic means in modern English newspapers, identifies various language techniques as one of the main reasons for the intensification of linguistic reflection of modern publicism

A native speaker often comments on words in terms of their origin. Socio-economic and cultural ties between linguistic groups, as well as the development of ethnic contacts contribute to the process of borrowing foreign language vocabulary. The speaker often enriches his speech with foreign words that are labeled with meta-operators. Pointing to borrowing, the speaker also expresses, through the meta-operators, an evaluative attitude toward the foreign word. Meta-operators pointing to dynamic processes in the vocabulary show that the vocabulary of the language develops according to the processes occurring in it: constant replenishment with new words and the disappearance of obsolete words.

Due to the fact that the sociolinguistic features of the modern press, in general, and the English, in particular, are interdependent with the dynamics of metalinguistic means, the work also classifies metalinguistic means of a newspa- 
per language according to graphic and orthographic signs punctuation marks and font.

Язык газеты традиционно отождествляют с газетно-публицистическим стилем. Однако номинация «язык газеты» чаще используется в современных исследованиях массовой коммуникации, где выделяются такие характеристики языка газеты как многостильность и многожанровость, его материальная неоднородность и стилевая полицентричность.

Газетный дискурс как процесс речевой коммуникации в печатных СМИ проявляется динамическим когнитивно-коммуникативным явлением. Газетный дискурс способствует обмену социально значимой актуальной информацией, т.К. является средой для создания газетного текста в условиях массовой коммуникации $[1$, с. 3]. К постоянным признакам газетного дискурса С. И. Виноградов относит письменную форму бытования дискурса, дистантность и реальность коммуникации, индивидуально-коллективного субъекта и рассредоточенного массового адресата. При этом многие ученые утверждают, что публицистический текст имеет особый фракультативный признак (персуазивность), позволяющий намеренно воздействовать на адресата [2, с. 284-285]. Н. И. Клушина, раскрывая принадлежность публицистического текста к персуазивному дискурсу, описывает данный текст как сложную иерархическую структуру, имеющую два плана выражения лингвистических способов убеждения: эксплицитного, т.е. открытого, влияющего на разумчитателя, и имплицитногоподтекстового, оказывающего непосредственное влияние на подсознание адресата [5, с. 11]. Сказанное выше позволяет отнести публицистический текст, реализующий интенцию убеждения и оказывающий сильный эфффект на своего адресата, к воздействующему типу дискурса.

Язык газеты характеризуется определенными стилистическими и риторическими параметрами. Он имеет ряд специфических свойств - связность предложений, общую тематическую структуру, схематическое представление информации. Анализ структуры газетного текста в разрезе изучения процесса коммуникации является важным помогает понять контекстуальную перспективу газетного языка. Интересным представляется фракт возможности изучения социального контекста, который содержит информацию об участниках коммуникации и о процессах создания сообщения

Текст газеты также характеризуются тем, что в нем быстрее находят отражение и фиксируются многочисленные изменения языковой действительности.

За последнее время публицистический дискурс и сам претерпел значительные изменения: расширилась его проблематика; появились новые жанры; он стал более эмоциональным и ироничным; стала заметна возросшая доля разговорной, стилистически сниженной лексики. Таким образом, произошла смена самой «коммуни-
Key words: metalanguage, metalanguage means, meta-operators, newspaper discourse, English newspapers.

кативной парадигмы»: диалогическая парадигма вытеснила монологическую.

Тематика британских изданий существенно определяет те средства, которые будут задействованы в трансляции информации. Английские редакторы нередко подстраивались под вкусь читателей, что стало визитной карточкой издательств. Действительно, британские издания всегда славились эмоциональной напряженностью высказывания, трансляцией тех жизненных особенностей, которые волнуют британцев. В современной британской публицистике именно этот стиль занял главенствующее место, отодвинув на второй план стиль научной прозы и стиль художественной речи. Несмотря на логическую последовательность в изложении фактов, развернутость высказывания, строгое деление на логические отрезки стиля художественной речи, публицистический стиль в условиях информационной эпохи внес существенные изменения.

Так, газетная публицистика и СМИ Великобритании оформило новую сферу лингвистики - медиалингвистику. Британская медиалингвистика разнообразна стилистическими, лексико-грамматическими и семантическими особенностями: используются различные языковые средства для передачи сообщения в конкретном стиле с учетом цели изложения и функции воздействия на читателя.

Опираясь на вышесказанное, отметим, что газетные издания, которые стали сегодня частью нашей жизни, и их речевая культура говорят о зависимости языка газеты от некоторых характеристик дискурсивного плана - типа издания и его концепции, спонсоров и рекламодателей, экстралингвистических, дополнительных параметров и др. [4, с. 44-46]. В этой связи сегодня многие исследователи изучают языковые явления, которые наслаиваются и порождаются прессой. Одним из таких явлений является «метаязык». Данный феномен применимо к газетной публицистике стал изучаться сравнительно недавно с точки зрения метаязыковой сущности языка газетной публицистики. Метаязык в газете отражает языковую реальность в неоклассической форме, старые модели перестали быть столь эффективными, поскольку язык представляет собой системно изменяющийся инструмент. В современной прессе язык трансформируется, что в принципе позволяет различным читателям искажать исходную инфрормацию.

В системе описания объекта в науке «метаязык» - одно из ключевых понятий, определяемый как язык «второго порядка», по отношению к которому естественный человеческий язык выступает как «язык-объект», то есть как предмет языковедческого исследования [8, с. 67]

В узком смысле метаязык - это не весь язык, а лишь его основные принципы. В широком - 
определенный стиль мышления, задающий дискурсу некоторые требования, например, доказательность, точность используемой терминологии предпочтение аргументированности и логичности и др. $[8$, с. 67$]$.

Ряд авторов (Ахманова О. С., Гвишиани Н. Б. Немец Г. П., Реформатский А. А.) утверждают, что в публицистике прослеживаются некоторые проблемы при анализе сущности метаязыка в прагматическом аспекте на уровне его стилей, жанров и разновидностей текстов. Причем основные проблемы выявляются в печатных изданиях

Как отмечалось нами выше, газетный язык реализует интенцию убеждения, оказывая мощный эфрфект на адресата, он также передает информацию и дает ее толкование. И здесь следует отметить, что сочетающаяся в таком тексте информационно-содержательная функция с функцией убеждения выражается различными метаязыковыми средствами.

Во всех современных жанрах публицистики можно наблюдать большое разнообразие языковых приемов, что обеспечивает усиление языковой рефлексии. При этом метаязыковые средства можно встретить в большом количестве в таких жанрах, как коммуникативные, аналитические, рекламные, а также в репортажах со спортивных соревнований.

Социолингвистический анализ лексики позволяет охарактеризовать и классифицировать слова, учитывая их особенности, которые обусловлены факторами внеязыкового и социально-исторического характера. В данном случае лексика может рассматриваться по сфере употребления (общеупотребительная - ограниченная в употреблении), по происхождению (исконная заимствованная) и по степени употребительности (актуальная - устаревшая). С помощью метаоператоров говорящий маркирует один из членов оппозиции, а другой остаётся нейтральным. Такое маркирование является показателем активизации современных процессов.

В русле нашего исследования считаем необходимым рассмотреть систему метаязыковых средств современной английской прессы на основе таких газет как The Independent, The Sun, The Guardian, The Times, Nouse, The Daily Telegraph, Morning Star и др.

Метаязык газеты «строится" посредством метаоператоров, которые могут указывать на во-первых, набор субъязыков современного говорящего, во-вторых, лексику с точки зрения происхождения и, в-третьих, динамические процессы в лексике.

Определим данные три группы метаоператоров, которые помогают выявить метаязыковые средства в статьях английских газет.

Первая группа метаоператоров характеризует набор субъязыков современного говорящего, который в своей речи может использовать тот или иной субъязык в зависимости от ситуации коммуникации, типа адресата и речевых жанров. Дпя указания на используемый в процессе общения субъязык говорящий вводит необходимый метасопроводитель. Например: «наречие + глагол «speak» в форме герундия». По такой модели строятся следующие метаоператоры: cinematically speaking, politically speaking medically speaking и т.д. [9, с. 147].

Наличие в речи подобных метаоператоров указывает на то, что говорящий использует выражения или лексемы, ограниченные определенной сферой употребления. Например: As a result, the supplier company, folksy speaking, hits on the dibs: the money for the goods are spent, there is no possibility to sell it, it takes a place in warehouses and hinders the production cycle. - В результаmе компания-поставщик, говоря народным языком, попадает на деньаи: деньаи на товар потрачены, продать его возможности нет, он занимает место на складах и мешает производственному циклу.

Вариантом данных оборотов будут высказывания, построенные по более простой модели: "союз «аs» + сущ. в им. п. + глагол «speak»/ "say» в H. вp.». Haпримep: He had an attempt to skip the question, as actors say, "with charm". У него была попытка пропустить этот вопрос, как говорят актеры, "за счет обаяния».

Ещё одной моделью метаоператоров, вводящих тот или иной субъязык, будет модель «әлагол "speak» в форме герундия + определенный артикль «the» + сущ. «language» с предл. "оf» + сущ. в род. пад.». Например: But what is left to us, the fans, or speaking the language of politics, to the electorate? - Но что же остается нам, болельщикам, или, выражаясь языком политиков, электорату?

Все перечисленные грамматические модели метавысказываний дают возможность говорящему создавать на примере существующих новые метаэлементы, которые потенциально заложены в языковой системе.

Проанализировав метаязыковые средства в 87 статьях различных жанров из 14 рубрик некоторых английских газет, мы пришли к выводу, что приведенные выше синонимичные метавысказывания, имеют разную частотность употребления. Для сравнения метаоператор speaking the language of young people - 122 раза, as young people say - 550; speaking the language of politics 25 , as politicians say -173 ; speaking the language of musicians -42 , as musicians say -395 ; speaking the language of doctors -114 , as doctors say -425 и т.д. Разная частотность употребления синонимичных метаединиц связана с тем, что говорящий выбирает более распространенный и менее сложный по грамматической форме вариант метаоператора. Такой выбор обусловлен законом экономии речевых усилий, а также тем, что метаоператоры, содержащие метаэлемент слова «speak» в форме герундия, относятся, скорее, к книжному стилю, чем к разговорному, поэтому реже употребляются в разговорной речи.

Рассматривая вторую группу метаоператоров, необходимо отметить, что носитель языка 
часто комментирует слова с точки зрения их происхождения. Активное развитие этнических контактов, социальных, экономических и культурных связей между языковыми коллективами способствуют процессу заимствования иноязычной лексики. Свою речь говорящий часто обогащает иноязычными словами, которые маркирует следующими метаоператорами: a foreign word, a borrowed word, a word appeared in our language $и$ т.д. [9, с. 147]. Например: 1) In 1601 appeared a new word in English language - "torrent". - B 1601 году в аналийском языке появилось новое слово - «mоррент». 2) Usual for everybody "military student" began to disappear, being replaced by a french word "cadet". - Всеми привьчное «курсант» начало исчезать, заменяясь французским словом «кадет». 3) German people have become accustomed to foreign word "parkour", but the words "workout" and "crossbar" for many people are still unusual. - Немцы уже привыкли к иноязычному слову «паркур», а вот «воркаут» и «кроссбар» для многих все еще в диковинку

Указывая на заимствования, говорящий также выражает через метаоператоры оценочное отношение к иностранному слову. С одной стороны, использование иностранных слов является показателем престижности, образованности и культуры современного человека, поэтому говорящий использует метаоператоры с положительной оценкой. С другой стороны, вхождение иноязычной лексики в какой-либо язык и её чрезмерное употребление вызывает у говорящего негативную реакцию, так как частое употребление иностранных слов нередко нарушает чистоту родного языка, а также приводит к непониманию между адресантом и адресатом. Например: 1) I don't like a foreign word "charisma", I prefer the divine spark. - Я не люблю иностранное слово «харизма», предпочитаю - божья искра. 2) Nowadays many people suffer from fear of having all the types of diseases. They're called "cyberchondriac", but I absolutely don't like this word. - Сегодня мноaие люди страдают оm страха иметь все виды болезней. Их называют «киберхондриками», но мне категорически не нравится это слово.

Основываясь на данных метаязыкового комментирования, исследователи могут расширить знания о языковой моде и моде как социальном и культурном феномене в целом. Метаоператоры, комментирующие модные иностранные слова, позволяют лингвистам создавать словари модных слов и своевременно пополнять словники иностранных слов.

Характеризуя третью группу метаоператоров, указывающих на динамические процессы 6 лексике, подчеркнем, что словарный состав языка развивается согласно происходящим в нем процессам: постоянное пополнение новыми словами и исчезновение устаревших слов [9, с. 148].

Заимствованная лексика или лексика, обозначающая социально значимые явления, становится популярной, актуальной и активно употребляется носителями языка. В свою очередь, слова, обозначающие неактуальные явления и объекты, становятся малоупотребительными, со временем такие спова могут потерять своё значение и совсем исчезнуть из языка. Эти два процесса указывают на то, что в словарном составе языка существует два слоя лексики: активная и пассивная.

Актуальные слова, активно употребляемые носителями языка, маркируются следующими метапоказателями: popular word, catchword, word is on everyone's lips, as they say today. Например: 1) Selfie, self-portrait, made by smartphone or webcam, won all the competitors in a fierce battle for a right to become the most popular word of the passing year. - Селфои, автопортрет, сделанный смартфоном или вебкамерой, победил в ожесточенной схватке всех конкурентов на право стать самым популярным словом уходящего zoda. 2) What motto, or as they say today, slogan do you stick to? - Какого девиза, или, как сейчас говорят, слогана вы придерживаетесь?

Для комментирования уходящих из употребления устаревших или устаревающих слов, которые выражают неактуальные понятия, говорящий использует метаоператоры: old word, ancient word, out-of-date word, unnecessary word и т.д. Напримep: 1) An ancient word "enlightener" better suits to this person. - Более всего этому человеку подходит старинное слово "просветитель». 2) A long word "refrigerator" is getting old, so it's better to use a word "fridge". - Длинное слово "Холодильная камера» устаревает, поэтому лучuе использовать слово «холодильник».

Так, метаоператоры, комментирующие социолингвистические характеристики лексики, позволяют лингвистам, во-первых, выявлять динамические процессы в лексической системе языка; во-вторых, выявлять круг лексики, подвергающейся этим динамическим процессам; в-третьих теоретически осмыслить и установить параметры модности слова и языковой моды в целом; в-четвертых, определить, какую оценку получают у говорящего активные процессы, происходящие в английском языке, и установить причину той или иной оценки.

При этом разговорная речь оказала огромное влияние на языковую норму, что обусловлено возросшим числом участников массовой коммуникации и личностным началом в речи, увеличением сферы спонтанного общения и появлением новых средств выражения. В связи с тем, что социолингвистические особенности современной прессы, в целом, и английской, в частности, взаимообусловлены с динамикой метаязыковых средств, в русле нашего исследования считаем необходимым классифицировать метаязыковые средства газетного языка по графико-орфографоческим признакам - по знакам препинания (кавычки, дефис, круглые скобки, квадратные скобки) и по шрифту (написание с прописной буквы). Рассмотрим метаязык английской газеты, выраженный каждым из перечисленных выше графико-орфографическим средством. 
Кавычки в письме играют огромную роль, ведь они помогают выделить прописанные в тексте важные слова. Именно с их помощью определяется основное, важное слово. Как правило в кавычки заключаются слова, обозначающие разного рода названия организаций, имена или применяемые в тексте в разговорном плане отдельные фразы. Например: 1) A word "telephone" is almost out-of-date but many people still use it in speech. - Слово «телефонный аппарат» почти устарело, но многие все еще используют ezo в речu. 2) The "graffiti" we see there will last for at least 70 years. - "Графpopumu», которое мы видим там, будет держаться как минимум 70 леm.

Тире означает всевозможные пропуски, такие как пропуск связки в сказуемом, пропуск членов предложения, пропуск противительных союзов Нельзя не отметить и другую функцию данного знака - смысловую, когда лексически не выражены значения условия, времени, сравнения, следствия, противопоставления и сопоставления Например: 1) It's hard enough for them - nobody here speaks English. - Им довольно трудно - никто здесь не говорит по-английски. 2) Florida Polytechnic University have introduced their brand new state of the art library, which houses no physical copies of books. Absolutely none - there's not even a single copy of The Great Gatsby tucked away on a shelf somewhere. - Политехнический Универcumem Флориды представил свой совершенно новый уровень технического развития библиотеки, не содержащей ни одного печатного издания книг. Абсолютного ни одного - нет даже единственного экземпляра Великого Гэтсби, запрятанного на какой-нибудь полке.

Квадратными скобками в цитатах обозначается авторский текст. Он помогает прояснить контекст самой цитаты. Например: 1) Another one [who's now a second year] said she found that when she played football at [university], they were like, "Oh, women have a team". - Другая [которая сейчас на втором курсе] сказала, что, когда играла в футmбол [в университете], услышала, как о них говорили: "О, у женщин есть команда». 2) Gendered language is used around a lot of these events telling [people] to act in different ways or to dress according to their gender. - Гендерный язык используется во мноаих из этих случаев, рассказывая [людям] как вести себя в различных ситуациях или как одеваться согласно их полу.

Круалые скобки являются своего рода приложением, то есть обособляют дополнительную информацию, которая не является чрезвычайно важной. Так, они позволяют расширить основную мысль в предложении при помощи добавления новой информации. В конечном итоге высказывание получается емким по форме, но информативным по сути. Например: 1) We have achieved a lot this year, what with our YuStart campaign and the illustrations (yes, there are illustrations in this one!) - Мы многого добились в этом году с помощью нашей кампании YuStart и иллюстраций (да, здесь есть и иллюстрации!). 2) Both these clever, multilingual, arty women educated their boyfriends (Jagger and Richards) about culture and art and style. - Обе эти умные, знающие иностранные языки, искусные женщины обучали свочх бойфррендов (Джагеера и Ричардса) культуре, искусству и стилю.

Восклицательный знак усиливает эмоциональную окраску повествования, используется для выражения изумления, сильного чувства или волнения. Например: It is essential to invest in good quality and good fit, otherwise you can end up looking a little like a ship at full sail (if that is the look you are going for then of course just rock it!) - Необходumo вкладывать деньаи в одежду хорошего качества и хорошо сидящую, в противном случае в конечном итоге вы можете выглядеть как корабль на всех парусах (но, если это тот наряд, который вам нужен, тогда, конечно, дерзайте!).

Использование прописных букө в слове или в части предложения подразумевает привлечение к тексту внимания, но порой из-за недостатка контраста между формами букв текста, набранного прописными, такое сообщение наоборот теряется по сравнению с обычным набором. Например: 1) But this week isn't for you, people, it's for the FRESHERS! - Но эта неделя не для вас, люди, она для ПЕРВОКУРСНИКОВ! 2) The hill has many words "written" on it, he says; and while some are in Icelandic, the increase in English - specifically "LIFE" and now "SEND NUDES" - suggests they're the work of tourists. - $\mathrm{OH}$ говорит, что на холме написано много слов. И хотя некоторые из них на исландском языке, большинство на английском - в частности, «ЖИЗНЬ» и «ФОТО В СТИЛЕ НЮ» - говорит, что это работа туристов.

Проведенный выше анализ английских газет позволил нам выявить 73 характерные метаязыковые единицы и классифицировать их по графико-орфографическим средствам: метаязык, выраженный кавычками, тире, круглыми и квадратными скобками, восклицательными знаками и прописными буквами. Данное исследование привело нас к выводу о том, что в рассмотренных газетах преобладает метаязык, представленный графически кавычками, что объясняется популярностью использования кавычек в текстах современных газет, целью которых служит определить важное слово или часть предложения в контексте.

Таким образом, анализ современных британских газет позволил нам рассмотреть особенности использования в них метаязыковых средств. Основные грамматические модели метавысказываний, такие как: «наречие + глагол «speak» 6 форме герундия», "союз "аs» + сущ. в им. п. + глагол «speak» в H. вр.», «глагол «speak» в форме герундия + определенный артикль «the» + cущ. "language» с предл. "оғ» + сущ. в род. пад. дают возможность говорящему создавать на примере существующих новые метаэлементы, которые потенциально заложены в языковой системе. При этом, метаоператоры, комментирующие 
социолингвистические характеристики лексики, позволяют лингвистам выявлять динамические процессы в лексической системе, выявлять круг лексики, подвергающейся этим динамическим процессам, определяя, какую оценку получают у говорящего активные процессы, происходящие в английском языке и устанавливая причину той или иной оценки.

\section{Литература}

1. Бобровская Г. В. Когнитивно-элокутивный потенциал газетного дискурса: монография. Волгоград: ВГПУ «Перемена», 2011. $318 \mathrm{c}$

2. Виноградов С. И. Язык газеты в аспекте культуры речи // Культура русской речи и эффективность общения. М.: Ин-т рус. яз. им. В. В. Виноградова, 1996. С. 281-317

3. Ионова Т. А. Лингвосемиотическая специфика текста комментария в современных британских СМИ // Вестник Волгоградского государственного университета. Серия 2: Языкознание. 2010. Т. 2. №2-12. С. 181-185

4. Казак М. Ю. Язык газеты: учеб. пособие. Белгород: ИД «Белгород», 2012. $120 \mathrm{c}$

5. Клушина Н. И. Интенциональные категории публицистического текста (на материале периодических изданий 2000-2008 гг.): автореф. дис. ... д-ра филол. наук. М., 2008. 57 с.

6. Кюрегян А. Л. Виды моделей провербиального кода и метаязык их формализованного описания // Филологические науки. Вопросы теории и практики. 2014. №1 - 1(31). С.76-79.

7. Макеева Л. Язык и реальность. URL: http://www.ruthenia.ru/logos/number/57/01.pdf (Дата обращения: 08.05.2019).

8. Пирвердиева Ю. А., Митрофанова О.Н.Сущностная характеристика понятия «метаязык» // Теоретические и прикладные аспекты развития научной мысли в современном мире: сборник статей Международной научно-практической конференции. В 4 ч. Ч.3. Уфа: АЭТЕРНА, 2017. С. 66-69.

9. Пирвердиева Ю. А., Митрофанова О.Н.Метаязыковые параметры лексической системы языка современных английских газет // Концепции устойчивого развития науки в современных условиях: сборник статей Международной научно-практической конференции (г. Екатеринбург). В 2 ч. Ч.2. Уфа: АЭТЕРНА, 2017. С. 146-149.

10. Julia Buckley. Tourists Carve "SEND NUDES" into Mossy Iceland Hill/ Independent URL: http://www.independent. co.uk/travel/news-and-advice/iceland-tourism-damage-graffiti-moss-send-nudes-nesjavellir-gunnar-birgisson-arnitryggvason-a7789156.html (Дата обращения: 08.05.2019).

11. Nouse // University of York's original student newspaper / September, 2014 URL: www.nouse.co.uk (Accessed 08.05.2019)

12. Suzanne Moore. Anita Pallenberg paid a high price for being a rock-star girlfriend // The Guardian. URL: https:// www.theguardian.com/commentisfree/2017/jun/14/anita-pallenberg-first-rock-chick-no-easy-gig-being-muse-rolling-stones (Accessed: 08.05.2019).

\section{References}

1. Bobrovskaja G. V. Kognitivno-jelokutivnyj potencial gazetnogo diskursa (Cognitive-Elocative Potential of Newspaper Discourse): monografija. Volgograd: Peremena publ., 2011. 318 p. (In Russian).

2. Vinogradov S. I. Jazyk gazety $\vee$ aspekte kul'tury rechi (Language of the newspaper in the aspect of speech culture) // Kul'tura russkoj rechi i jeffektivnost' obshhenija. Moscow: Institute Russian Language named after V. Vinigradov publ., 1996. P. 281-317. (In Russian).

3. Ionova T. A. Lingvosemioticheskaja specifika teksta kommentarija v sovremennyh britanskih SMI (Linguosemiotic specifics of commentary text in modern British media) // Vestnik Volgogradskogo gosudarstvennogo universiteta. Serija 2 : Jazykoznanie. 2010. Vol.2. No.2-12. P.181-185. (In Russian).

4. Kazak M. Ju. Jazyk gazety (Newspaperlanguage): textbook. Belgorod: Belgorod publ., 2012. 120 p. (In Russian)

5. Klushina N. I. Intencional'nye kategorii publicisticheskogo teksta (na materiale periodicheskih izdanij 2000-2008 gg.) (Intentional categories of journalistic text (based on material from periodicals 2000-2008): abstract of thesis. Moscow, 2008. 57 p. (In Russian).

6. Kjuregjan A. L. Vidy modelej proverbial'nogo koda i metajazyk ih formalizovannogo opisanija (Types of models of the proverbial code and metalanguage of their formalized description) // Filologicheskie nauki. Voprosy teorii i praktiki. 2014. No. 1-1(31). P. 76-79. (In Russian).

7. Makeeva L. Jazyk i real'nost' (Language and reality). URL: http://www.ruthenia.ru/logos/number/57/01.pdf (Accessed 08.05.2019). (In Russian).

8. Pirverdieva Ju. A., Mitrofanova O. N. Sushhnostnaja harakteristika ponjatija «metajazyk» (The essential characteristic of the concept of "metalanguage") // Teoreticheskie i prikladnye aspekty razvitija nauchnoj mysli v sovremennom mire: sbornik statej Mezhdunarodnoj nauchno-prakticheskoj konferencii. In 4 Parts. Part.3. Ufa: AJeTERNA publ., 2017. P. 66-69. (In Russian).

9. Pirverdieva Ju. A., Mitrofanova O. N. Metajazykovye parametry leksicheskoj sistemy jazyka sovremennyh anglijskih gazet (Metalanguage parameters of the lexical system of the language of modern English newspapers) // Koncepcii ustojchivogo razvitija nauki v sovremennyh uslovijah: sbornik statej Mezhdunarodnoj nauchno-prakticheskoj konferencii (g. Ekaterinburg). In 2 Parts. Part.2. Ufa: AJeTERNA, 2017. P. 146-149. (In Russian).

10. Julia Buckley. Tourists Carve "SEND NUDES" into Mossy Iceland Hill / Independent URL: http://www.independent. co.uk/travel/news-and-advice/iceland-tourism-damage-graffiti-moss-send-nudes-nesjavellir-gunnar-birgisson-arnitryggvason-a7789156.html (Accessed: 08.05.2019). (In Russian).

11. Nouse // University of York's original student newspaper / September, 2014 URL: www.nouse.co.uk (Accessed 08.05.2019) 
12. Suzanne Moore. Anita Pallenberg paid a high price for being a rock-star girlfriend // The Guardian. URL: https:// www.theguardian.com/commentisfree/2017/jun/14/anita-pallenberg-first-rock-chick-no-easy-gig-being-muse-rolling-stones (Accessed: 08.05.2019).

\section{Сведения об авторе}

Пирвердиева Юлия Аванесовна - кандидат педагогических наук, доцент кафедры романо-германской филологии и лингводидактики гуманитарного института Северо-Кавказского федерального университета (Ставрополь) / pirverd@yandex.ru

\section{Information about the author}

Pirverdieva Julia - PhD in Pedagogy, Associate Professor, Chair of Romano-Germanic Philology and Lingvodidactics, Humanities Institute, North-Caucasus Federal University (Stavropol) / pirverd@yandex.ru 